\title{
Antiretroviral treatment failure and associated factors among HIV patients on first-line antiretroviral treatment in Sekota, northeast Ethiopia
}

\author{
Jemberu Nega' ${ }^{1}$ Solomon Taye ${ }^{1}$, Yihenew Million ${ }^{*} \mathbb{C}$, Chaturaka Rodrigo $^{2}$ and Setegn Eshetie
}

\begin{abstract}
Background: Antiretroviral treatment has played a pivotal role in the reduction of HIV/AIDS-related morbidity and mortality. However, treatment options can be impaired by the development of antiretroviral treatment failure. Regular monitoring of the Human Immunodeficiency Virus treatment outcome via viral load tests is the key approach. There is a scarcity of information about HIV treatment failure and risk factors in the study area. Therefore, the study was aimed to assess antiretroviral treatment failure and associated factors among patients on first-line antiretroviral treatment at Tefera Hailu Memorial Hospital, Sekota, northeast Ethiopia.
\end{abstract}

Methods: A hospital-based cross-sectional study was conducted on 295 patients on first-line antiretroviral treatment from Nov. 2018 to Apr. 2019. Socio-demographic and clinical variables were collected using a pretested questionnaire, and blood specimen was collected for PCR viral load and CD4 + cell count estimation. Data were entered into Epi-Info and exported to SPSS for analysis. A binary logistic regression model was used to identify associated factors, and $P$ value $<0.05$ was considered as statistically significant.

Results: Of the 295 subjects on first-line ART, 49 (16.6\%) and 18 (6.1\%) experienced virological and immunological failures, respectively. The failure of the former was associated with poor adherence (AOR: 6.367, $P<0.001$ ), CD4 + count $<500$ cells $/ \mu \mathrm{L}$ (AOR: $4.78, P=0.031$ ) and shorter (6-24 months) duration on ART (AOR: $0.48, P=0.048$ ), while poor treatment adherence (AOR: 11.51, $P=0.012$ ) and drug interruption (AOR: 6.374, $P=0.039$ ) were the independent risk factors for latter. Immunological tests to predict virological failures showed as sensitivity, specificity, PPV, and NPV were $20.4 \%, 96.7 \%, 55.5 \%$, and $86.0 \%$, respectively.

Conclusions: The rate of ART failure was considerably high. Poor adherence, low CD4 + count, prolonged ART, and drug interruption were found to be the most predictor variables for virological and immunological failures. The discrimination power of the immunological parameter was low in comparison to virological measurements as standard methods. Therefore, the study highlighted the need for more attention and efforts to curb associated factors and maximize virological tests for monitoring treatment failures.

Keywords: Antiretroviral treatment failure, Risk factors, Northeast Ethiopia

\footnotetext{
${ }^{*}$ Correspondence: millionbeza@gmail.com

1 Department of Medical Microbiology, School of Biomedical

and Laboratory Sciences, College of Medicine and Health Sciences, University of Gondar, PO Box 196, Gondar, Ethiopia

Full list of author information is available at the end of the article
}

\section{Background}

Following the epidemic of HIV/AIDS, the global expansion of the combination antiretroviral treatment (ART) has been the primary contributor to the $51 \%$ decline AIDS-related deaths, from a peak of 1.9 million (1.4-2.7 
million) in 2004 to 0.94 million (0.67-1.3 million) in 2017. The scaling up of ART was a critical turning point in the clinical management of the HIV/AIDS disease and the gradual evolution of HIV infection into a chronic non-fatal condition by restoring the immune function and suppressing the virus to an undetectable level. This resulted in preventing the transmission of the virus to other uninfected individuals.

Globally, 21.7 million (59\%) people living with HIV/ AIDS (PLHA) accessed treatment in 2017 and Africa accounted for 15.3 million on ART [1]. In Ethiopia, ART began in 2003 and free ART was launched in 2005. By the test and treat all patients policy of WHO 2016, above 73,800 HIV positive patients required ART in Ethiopia. However, only near half, 426,000, took ARV nationwide [2-4]. Despite the WHO recommended viral load monitoring to ensure viral load suppression and early detect ART treatment failure, large gaps remain in global access, particularly in low- and middle-income countries and rural areas. Individual-level viral load is the recommended measure of antiretroviral therapy efficacy; it indicates treatment adherence and the risk of transmitting HIV [5].

Ethiopia has adopted the WHO plan "End the AIDS epidemic by 2020 to achieve the target of the three 90\%'s (know HIV status-get treatment-viral suppression)" ambitious plan. However, due to inaccessibility, costs and technical demands of the HIV RNA test, immunologic $(\mathrm{CD} 4+\mathrm{T}$ cell test) is still widely recommended in Ethiopia for monitoring treatment failures. But immunologic parameters have a lower accuracy of identifying virologic failures, leading to premature changes or continuous uses of failed regimens. This leads to more complex HIV drug failures, and the health impact increases morbidity and mortality rates in settings where virologic tests are not available.

There has been a marked paucity of information on ART failure and associated risk factors in Ethiopia, including in the study area. Besides, the lack of early detection of the virological failure is often coupled with delays in switching to efficacy drugs. Such conditions weakened the ability to prevent treatment failure and led to accumulation of further HIV-DR at individual and population level. Therefore, this study was conducted to assess the extent of antiretroviral treatment failure and its associated factors among HIV patients on first-line ART at Tefera Hailu Memorial Hospital, Sekota, northeast Ethiopia.

\section{Methods}

\section{Study area}

The study was conducted at Tefera Hailu Memorial Hospital in Sekota town, the capital of Waghimra zone, east Amhara region, $720 \mathrm{~km}$ north of Addis Ababa and $320 \mathrm{~km}$ north of Dessie. The hospital provided ART and referral case services to nearly half amillion people. The hospital reported that about 1760 patients started ART until October 2018, and that 889 were on treatment at that moment. The hospital laboratory had a separate section for CD4 + count and an estimated 2000 blood specimens were delivered for the purpose annually from the hospital and the surrounding health centers. Blood specimens were collected for viral load determination, processed and made ready for transport to Dessie branch of the Amhara Public Health Institute.

\section{Study design and population}

A hospital-based cross-sectional study was conducted on 295 adolescent and adult PLHA patients who were on first line ART follow ups at Tefera Hailu Memorial Hospital from Nov. 2018 to Apr. 2019. Systematic random sampling technique was used to enroll the participants Sample size was determined using the single population proportion formula, with the following assumption, $\mathrm{n}=$ sample size, $\mathrm{d}=0.05 ; \mathrm{P}=0.222$, which was reported in the previous study in Gondar [6] and $\mathrm{Z} \alpha / 2=1.96$ by assuming a $95 \%$ confidence level. The minimum sample size was $(n=266)$, and by considering a $10 \%$ nonresponse rate the final sample is 295 .

\section{Inclusion criteria}

All adolescent and adult patients who were on first-line ART and had at least a six-month follow up and volunteerd to participate were included in the study, while, patients who were on second-line ART and had incomplete data before the study were excluded.

\section{Study variables}

Antiretroviral treatment failure defined according to the WHO 2016 guideline was the outcome variable [2]. Age, gender, educational level, occupation, marital status, distance from home to clinic, alcohol usage, disclosure, and monthly income were socio-demographic variables. WHO clinical stages, CD4+ counts and ART regimen (baseline, current status), level of adherence, drug interruption, functional status, ART dose, frequency of drug substitute, tuberculosis in the course of therapy, duration of ART, and HIV prophylaxis were clinical variables.

\section{Definition of terms}

Virological failure is defined as when antiretroviral therapy (ART) fails to suppress viral replication to lower than 1000 copies $/ \mathrm{mL}$, while immunological failure is a fall of $\mathrm{CD} 4+$ count below 250 cells $/ \mu \mathrm{L}$ following clinical failure, or persistent CD4+ count below 100 cells/ $\mu \mathrm{L}$ [7]. 
Socio-demographic and clinical data collection

Socio-demographic and clinical (baseline, follow up and current patient status) data were collected by expert nurses from patient medical files and face to face interviews using a structured pre-tested questionnaire. The questionnaire was adapted from the WHO risk assessment tool for HIV treatment failure and was developed by using literature, on risk assessment for HIV treatment failure.

\section{Specimen collection and processing}

Expert laboratory staff members collected $4 \mathrm{~mL}$ and $2 \mathrm{ml}$ of whole blood into plasma preparation tube (PPT) and ethylenediaminetetraacetic acid (K3 EDTA) tube, for viral load test and CD4 counts, respectively, from each participants. After $30 \mathrm{~min}$, PPT was centrifuged at $1500 \mathrm{rpm}$ for $10 \mathrm{~min}$ to separate plasma (top), in between separator gel and the cell (bottom). Then, the plasma containing PPT was transported in a triple package sample transportation box at $2-8{ }^{\circ} \mathrm{C}$ to Amhara Hublic Health Institute Dessie center, by an orientated laboratory assistant.

\section{Determination of $\mathrm{CD} 4+\mathrm{T}$ lymphocyte}

The CD4 $+\mathrm{T}$ cell count determination was carried out using $50 \mu \mathrm{l}$ of EDTA whole blood added to the cartridge and run by the Becton-Dickinson Biosciences (BD) Fluorescent Activated Cell Sorter (FACS) Presto near patient machines. In the analysis, the software identifies the T-Lymphocyte populations and calculates the absolute counts of CD4+ cells and results printed out.

\section{Determination of viral load}

RNA extraction from $0.2 \mathrm{~mL}$ of plasma and amplification reagent (master mix) preparation was done by using the Abbott m2000sp HIV-1 assay. Then both extracted RNA and master mix were dispensed into a 96 deep well plate (made ready for amplification). In the Abbott m2000rt analyzer extracted RNAs were changed to complementary deoxyribonucleic acid (DNA) by reverse transcriptase polymerase chain reaction (RT-PCR), and DNA was continued for amplification. Then, the DNA product was measured using the Abbott m2000rt quantitative Real-Time HIV-1 assay with HIV-1 RNA detection level depend on the amount of sample ranging 40 to $10 \times 10^{6}$ copies $/ \mathrm{ml}$.

\section{Quality control}

The quality of the data was confirmed by pre-testing the questionnaire on $5 \%$ of respondents other than those involved in the actual study and by proper designing. Before beginning the actual data collection, training was given to data collectors, and the questionnaire was reviewed and checked. Data collectors were supervised during the process and given feedback by the principal investigator every morning. The whole process of work was assured and approved by advisors.

The Abbott Real-time HIV-1 (m2000sp) assay internal control an RNA sequence unrelated to the HIV-1 target sequence was introduced into each specimen at the beginning of sample preparation. This unrelated RNA sequence was simultaneously amplified by RT-PCR and served as an internal control (IC) to demonstrate that the process proceeded correctly for each sample. Also, negative, low positive and high positive controls were used. For the CD4 test, the FACS Presto machine had internal performance control. Both viral load and CD4 tests were done by experts who used standard operating procedures.

\section{Data analysis and interpretation}

Data were cleaned and checked for completeness and entered into EPI-Info version 7 and exported to SPSS version 20 for analysis. Descriptive statistics (frequencies, percentages, medians, and ranges) were used to describe results. The binary logistic regression analysis was used to determine univariable associations with ART treatment failures. All factors $(P \leq 0.2)$ were finally tested by the multivariable logistic regression for adjusted odds ratios to decrease confounding errors of the independent variables for treatment failure. P-value $<0.05$ was considered as statistically significant for treatment failure. Using a two-by-two contingency table, sensitivity, specificity, positive predictive value (PPV), and negative predictive value (NPV), were calculated to determine the validity of the immunological tests for predicting virological failures. Data were also prepared by using tables. The virological and immunological treatment failures were defined according to the WHO 2016 guideline for the use of ART drugs.

\section{Results}

\section{Sociodemographic information}

A total of 295 HIV positive individuals, 169 (57\%) of whom were female, on first-line ART regimens participated. The median age of the participants was 37 years (IQR: $30-43)$, and the majority, 115 (39\%), were aged between 30 and 39; 129 (43.7\%) were married; nearly three-fourths, 215 (72.9\%), attended primary school and above; 143 (48.5\%) were self-employed; distance from home to hospital was $>10 \mathrm{~km} ; 79(27 \%)$ of the participants were rural dwellers (Table 1 ). 
Table 1 The distribution of virological failure per socio-demographic factors at Tefera Hailu Memorial Hospital, Sekota, northeast Ethiopia, 2019

\begin{tabular}{|c|c|c|c|c|c|}
\hline Variables & Category & $N=295$ & \% From $\mathrm{N}$ & $\mathrm{VTF}=49$ & $\%$ From failure \\
\hline \multirow[t]{5}{*}{ Age } & $10-19$ & 20 & 6.8 & 8 & 16.33 \\
\hline & $20-29$ & 42 & 14.2 & 7 & 14.29 \\
\hline & $30-39$ & 115 & 39 & 17 & 34.69 \\
\hline & $40-49$ & 89 & 30.2 & 14 & 28.57 \\
\hline & $50+$ & 29 & 9.8 & 3 & 6.12 \\
\hline \multirow[t]{2}{*}{ Gender } & Female & 169 & 57 & 28 & 57.14 \\
\hline & Male & 126 & 43 & 21 & 42.86 \\
\hline \multirow[t]{4}{*}{ Marital status } & Single & 54 & 18.3 & 15 & 30.61 \\
\hline & Married & 129 & 43.7 & 20 & 40.82 \\
\hline & Divorced & 76 & 25.8 & 10 & 20.41 \\
\hline & Widowed & 36 & 12.2 & 4 & 8.16 \\
\hline \multirow[t]{4}{*}{ Education status } & Not read/write & 80 & 27.1 & 9 & 18.37 \\
\hline & Primary & 108 & 36.6 & 24 & 48.98 \\
\hline & Secondary & 67 & 22.7 & 13 & 26.53 \\
\hline & Above secondary & 40 & 13.6 & 3 & 6.12 \\
\hline \multirow[t]{4}{*}{ Occupational status } & Gov. employee & 75 & 25.4 & 8 & 16.33 \\
\hline & Self-employee & 143 & 48.5 & 24 & 48.98 \\
\hline & Unemployed & 43 & 14.6 & 12 & 24.49 \\
\hline & Farmer & 34 & 11.5 & 5 & 10.20 \\
\hline \multirow[t]{2}{*}{ Alcohol use } & No & 246 & 83.4 & 42 & 85.71 \\
\hline & Yes & 49 & 16.6 & 7 & 14.29 \\
\hline \multirow[t]{2}{*}{ Distance to ART clinic } & $<10 \mathrm{~km}$ & 216 & 73.2 & 36 & 73.47 \\
\hline & $>10 \mathrm{~km}$ & 79 & 26.8 & 13 & 26.53 \\
\hline
\end{tabular}

VTF virological treatment failure, $N$ total participants, ETB Ethiopia Birr, alcohol never allowed for patients on ART, age category according to Ethiopia ART guideline 2017

\section{Clinical information}

The baseline and current median CD4+ counts were 198 (IQR: 135-314) and 414 cells/ $\mu \mathrm{L}$ (IQR: 309-544), respectively. Participants were on first-line ART with a median follow up time of 83 months (IQR 53-116). At ART initiation, 183 (62.37\%) patients were ambulatory by their functional status, and $112(38 \%)$ were baseline clinical stage III and IV. In contrast, during data collection, only $2.03 \%$ of the participants were in clinical stage III and IV. Presentations were not even observed among the respondents (Table 2).

At the time of treatment initiation, different classes of first-line ART drugs were prescribed; patients on azidothymidine (AZT), tenofovir disoproxil fumarate (TDF), and stavudine (d4T) based regimens were 119 (40.3\%), 110 (37.3\%) and 66 (22.4\%), respectively. As illustrated in (Table 2), during the implementation of the study, different types of first-line ART regimens, like AZT-based 144 (48.8\%) regimens were given to patients. On the other hand, TDF-based regimens were prescribed to 151 (51.2\%) patients; $87(29.5 \%)$ of the participants have received substitution (other first lines) for different reasons; for instance, d4T was outdated due to physiological toxicity.

\section{Virological treatment failure and related risk factors}

The prevalence of virological failure among respondents was 49 (16.6\%; 95\% CI 12.5-20.9), of whom 28 (57.1\%) were females. On the other hand, effective viral suppression, $<1000$ copies/ml, was noted among $246(83.4 \%)$ of the participants.

The multivariable logistic regression showed that poor drug adherence $(<95 \%)$ was identified as one of the independent risk factors for virological treatment failure. Patients with poor adherence experienced just above six times higher odds to develop treatment failure at (AOR $=6.367,95 \%$ CI 2.35-17.2, $\mathrm{P}<001$ ). participants with $\mathrm{CD} 4+$ counts $<500$ cells $/ \mu \mathrm{L}$ were almost five times more likely to develop virological treatment failure (AOR: 4.78, 95\% CI 1.15-19.77), $\mathrm{P}=0.031$ ) in comparison with those who had more CD4+count. Furthermore, treatment duration was also another predictor variable; only patients who followed treatments for 6-24 months had the chance to minimize treatment failure by nearly $50 \%$ 
Table 2 The distribution of virological failure per clinical factors at Tefera Hailu Memorial Hospital, Sekota, northeast Ethiopia, 2019

\begin{tabular}{|c|c|c|c|c|c|}
\hline Variables & Category & $N=295$ & $\%$ from $\mathrm{N}$ & $\mathrm{VTF}=49$ & $\%$ \\
\hline \multirow[t]{5}{*}{ Current ART regimen } & $1 \mathrm{c}$ & 53 & 18.0 & 16 & 32.65 \\
\hline & $1 d$ & 82 & 27.8 & 12 & 24.49 \\
\hline & 1e & 135 & 45.8 & 15 & 30.61 \\
\hline & 1f & 16 & 5.4 & 2 & 4.08 \\
\hline & $4 c$ & 9 & 3.1 & 4 & 8.16 \\
\hline \multirow[t]{6}{*}{ Baseline ART regimen } & $1 a$ & 26 & 8.8 & 4 & 8.16 \\
\hline & $1 b$ & 40 & 13.6 & 8 & 16.33 \\
\hline & $1 c$ & 37 & 12.5 & 8 & 16.33 \\
\hline & $1 d$ & 68 & 23.1 & 12 & 24.49 \\
\hline & 1e & 110 & 37.3 & 11 & 22.45 \\
\hline & $4 c$ & 14 & 4.7 & 6 & 12.24 \\
\hline \multirow[t]{2}{*}{ Drug substitution } & None & 208 & 70.5 & 31 & 63.27 \\
\hline & Once & 87 & 29.5 & 18 & 36.73 \\
\hline \multirow[t]{4}{*}{ Current CD4 result } & $\leq 100$ & 23 & 7.8 & 14 & 28.57 \\
\hline & $101-250$ & 86 & 29.2 & 20 & 40.82 \\
\hline & $251-500$ & 88 & 29.8 & 11 & 22.45 \\
\hline & $501+$ & 98 & 33.2 & 4 & 8.16 \\
\hline \multirow[t]{3}{*}{ Current clinical stage } & । & 265 & 89.8 & 34 & 69.39 \\
\hline & $\|$ & 24 & 8.13 & 12 & 24.49 \\
\hline & III & 6 & 2.03 & 3 & 6.12 \\
\hline \multirow[t]{4}{*}{ Baseline clinical stage } & । & 59 & 20.0 & 7 & 14.29 \\
\hline & $\|$ & 124 & 42.0 & 21 & 42.86 \\
\hline & III & 98 & 33.2 & 18 & 36.73 \\
\hline & IV & 14 & 4.7 & 3 & 6.12 \\
\hline \multirow[t]{2}{*}{ The dose of ART per day } & Once & 131 & 44.4 & 15 & 30.61 \\
\hline & Twice & 164 & 55.6 & 34 & 69.39 \\
\hline \multirow[t]{2}{*}{ Drug interruption } & No & 261 & 88.5 & 37 & 75.51 \\
\hline & Yes & 34 & 11.5 & 12 & 24.49 \\
\hline \multirow[t]{2}{*}{ Drug adherence } & $\geq 95 \%$ & 189 & 64.1 & 11 & 22.45 \\
\hline & $<95 \%$ & 106 & 35.9 & 38 & 77.55 \\
\hline \multirow[t]{2}{*}{ Prophylaxis use } & No & 285 & 96.6 & 44 & 89.80 \\
\hline & Yes & 10 & 3.4 & 5 & 10.80 \\
\hline \multirow[t]{3}{*}{ Baseline function status } & Bedridden & 28 & 9.5 & 7 & 14.29 \\
\hline & Ambulatory & 184 & 62.4 & 28 & 57.14 \\
\hline & Working & 83 & 28.1 & 14 & 28.57 \\
\hline \multirow[t]{2}{*}{ TB history } & No & 242 & 82 & 36 & 73.47 \\
\hline & Yes & 53 & 18 & 13 & 26.53 \\
\hline \multirow[t]{2}{*}{ Disclosure } & No & 71 & 24.1 & 10 & 20.41 \\
\hline & Yes & 224 & 75.9 & 39 & 79.59 \\
\hline \multirow[t]{4}{*}{ Duration/month on ART } & $6-24$ & 29 & 9.8 & 1 & 2.04 \\
\hline & $25-48$ & 39 & 13.2 & 4 & 8.16 \\
\hline & $49-72$ & 57 & 19.3 & 7 & 14.29 \\
\hline & $73+$ & 170 & 57.6 & 37 & 75.51 \\
\hline \multirow[t]{4}{*}{ Baseline CD4 result } & $\leq 100$ & 150 & 50.8 & 26 & 53.06 \\
\hline & $101-250$ & 88 & 29.8 & 15 & 30.61 \\
\hline & $251-500$ & 28 & 9.5 & 3 & 6.12 \\
\hline & $501+$ & 29 & 9.8 & 5 & 10.20 \\
\hline
\end{tabular}


Table 3 Associated risk factors with virological failure at the Tefera Hailu Memorial Hospital, Sekota, northeast Ethiopia, 2019

\begin{tabular}{|c|c|c|c|c|c|}
\hline Variables & Category & COR $(95 \% \mathrm{Cl})$ & P-V & AOR $(95 \% \mathrm{Cl})$ & P-V \\
\hline \multirow[t]{5}{*}{ Age } & $10-19$ & $5.78(1.3-25.71)$ & $0.021^{*}$ & $4.39(0.2-116.5)$ & 0.37 \\
\hline & $20-29$ & $1.73(0.41-7.35)$ & 0.45 & $2.87(0.32-25.4$ & 0.34 \\
\hline & $30-39$ & $1.50(0.41-5.52)$ & 0.54 & $1.12(0.16-7.72)$ & 0.91 \\
\hline & $40-49$ & $1.62(0.43-6.08)$ & 0.47 & $2.36(0.35-15.9)$ & 0.37 \\
\hline & $50+$ & & 1 & & 1 \\
\hline \multirow[t]{4}{*}{ Education status } & Not read/write & $1.56(0.4-6.13)$ & 0.52 & $0.97(0.094-83.03)$ & 0.98 \\
\hline & Primary & $3.52(1.0-12.43)$ & 0.05 & $1.58(0.195-12.9)$ & 0.66 \\
\hline & Secondary & $2.97(0.79-11.15)$ & 0.10 & $2.19(0.26-18.5)$ & 0.47 \\
\hline & Above secondary & & 1 & & 1 \\
\hline \multirow[t]{5}{*}{ Current ART regimen } & $1 \mathrm{c}$ & $0.54(0.13-2.28)$ & 0.41 & $2.1(0.09-48.9)$ & 0.64 \\
\hline & $1 d$ & $0.21(0.05-0.91)$ & $0.037^{*}$ & $0.4(0.01-12.6)$ & 0.60 \\
\hline & $1 e$ & $0.16(0.04-0.64)$ & $0.01^{*}$ & $0.14(0.003-5.6)$ & 0.29 \\
\hline & $1 f$ & $0.179(0.02-1.29)$ & 0.08 & $0.33(0.007-17.2)$ & 0.58 \\
\hline & $4 c$ & & 1 & & 1 \\
\hline \multirow[t]{6}{*}{ Baseline ART regimen } & $1 \mathrm{a}$ & $0.24(0.054-1.08)$ & 0.06 & $0.29(0.005-15.4)$ & 0.54 \\
\hline & $1 b$ & $0.33(0.09-1.24)$ & 0.10 & $1.13(0.02-76.0)$ & 0.95 \\
\hline & $1 c$ & $0.37(0.09-1.37)$ & 0.136 & $0.39(0.01-15.9)$ & 0.62 \\
\hline & $1 d$ & $0.28(0.08-0.97)$ & $0.046^{*}$ & $1.15(0.02-65.5)$ & 0.94 \\
\hline & $1 e$ & $0.15(0.04-0.50)$ & $0.002^{*}$ & $1.18(0.02-80.3)$ & 0.94 \\
\hline & $4 c$ & & 1 & & 1 \\
\hline \multirow[t]{4}{*}{ Current CD4 result } & $\leq 100$ & 36.55 (9.9-94.77) & $<0.001^{*}$ & $42.36(7.43-79.6)$ & $0.000^{*}$ \\
\hline & $101-250$ & $7.12(2.33-21.8)$ & $0.001^{*}$ & $12.1(2.76-53.1)$ & $0.001^{*}$ \\
\hline & $251-500$ & $3.36(1.03-10.96)$ & $0.045^{*}$ & $4.78(1.15-19.77)$ & $0.031^{*}$ \\
\hline & $501+$ & & 1 & & \\
\hline \multirow[t]{3}{*}{ Current clinical stage } & 1 & & 1 & & 1 \\
\hline & $\|$ & 6.79 (2.82-16.34) & $<0.001^{*}$ & $1.1(0.09-13.3)$ & 0.94 \\
\hline & III & 6.79 (1.32-35.03) & $0.022^{*}$ & $3.15(0.83-12.0)$ & 0.09 \\
\hline \multirow[t]{2}{*}{ Dose of ART per day } & Once & $0.49(0.25-0.95)$ & $0.036^{*}$ & $0.48(0.06-4.1)$ & 0.50 \\
\hline & Twice & & 1 & & \\
\hline \multirow[t]{2}{*}{ Drug interruption } & No & & 1 & & 1 \\
\hline & Yes & $3.30(1.50-7.24)$ & $0.003^{*}$ & $1.19(0.37-3.86)$ & 0.77 \\
\hline \multirow[t]{2}{*}{ Drug adherence } & $\geq 95 \%$ & & 1 & & 1 \\
\hline & $<95 \%$ & $9.04(4.37-18.7)$ & $<0.001^{*}$ & $6.36(20.35-17.2)$ & $0.000^{*}$ \\
\hline \multirow[t]{2}{*}{ Prophylaxis } & No & & 1 & & 1 \\
\hline & Yes & $3.88(10.18-12.77)$ & $0.026^{*}$ & $5.42(0.98-29.9)$ & 0.053 \\
\hline \multirow[t]{2}{*}{ TB history } & Yes & $1.86(0.9-1.80)$ & 0.09 & $1.53(0.53-4.45)$ & 0.44 \\
\hline & No & & 1 & & 1 \\
\hline \multirow[t]{2}{*}{ Immunologic failure } & No & & 1 & & 1 \\
\hline & Yes & $7.63(2.84-20.5)$ & $0.000^{*}$ & $0.06(0.003-1.5)$ & 0.088 \\
\hline \multirow[t]{4}{*}{ Duration on ART (months) } & $6-24$ & $0.13(0.02-0.97)$ & $0.047^{*}$ & $0.48(0.01-0.97)$ & $0.048^{*}$ \\
\hline & $25-48$ & $0.41(0.14-1.23)$ & 0.11 & $0.37(0.07-1.87)$ & .23 \\
\hline & $49-72$ & $0.50(0.21-1.20)$ & 0.122 & $0.24(0.06-0.97)$ & 0.06 \\
\hline & $73+$ & & 1 & & 1 \\
\hline
\end{tabular}


(AOR: $0.4895 \%$ CI $0.012-0.973, \mathrm{P}=0.048$ ) compared to those on treatment for over 72 months (Table 3 ).

Immunological treatment failure and related risk factors Of the 295 participants, 18 (6.1\%) (95\% CI 3.4-9.5) faced immunological failures, of these $11(61.1 \%)$ were male. Among immunological failed participants, 10 (55.5\%) of them had also viral failure and 8 (44.4\%) encountered only CD4 + failure. Patients with poor drug adherence were intriguingly found to be 11.51 times more likely to experience immunological failure (AOR: 11.51, $95 \% \mathrm{CI}=1.72-77.3, \mathrm{P}=0.012)$ compared to those who adhered (>95\%). Similarly, patients who interrupted drugs had 6.374 times higher odds of immunological failure (AOR: 6.374, 95\% CI 1.093-37.165, $\mathrm{P}=0.039$ ) than those who did not.

\section{Validity of immunological tests for virological failure prediction}

In the present study, immunologic failure showed low predictive values for detecting the virological failures. Using the two-by-two contingency table, screening immunologic failure was compared to the golden standard virological failure, and the sensitivity, specificity, PPV, and NPV were $20.4 \%, 96.7 \%, 55.5 \%$, and $86 \%$, respectively (Table 4).

\section{Discussion}

It is clear that the plasma viral load test is now increasingly used to check the success of patients on antiretroviral therapy since several studies have shown that the risk for HIV transmission is very low when the viral load is lower than 1000 copies $/ \mathrm{ml}$. Our study revealed that about $83.4 \%$ of the respondents' viral load was below 1000 cop$\mathrm{ies} / \mathrm{ml}$ (suppressed), and most of them had chances to decrease treatment failure, minimize transmission to others and the risks for clinical conditions, indicating that a combination of ART was highly effective for

Table 4 The predictive power of immunological criteria to detect virological treatment failure at Tefera Hailu Memorial Hospital, Sekota, northeast Ethiopia, 2019

\begin{tabular}{|c|c|c|c|}
\hline \multirow[t]{2}{*}{ Immunological failure } & \multicolumn{2}{|c|}{$\begin{array}{l}\text { Virological failure (>1000 } \\
\text { copies/ml) }\end{array}$} & \multirow[t]{2}{*}{ Total } \\
\hline & Yes & No & \\
\hline Yes (<500 cells/ $\mu \mathrm{L})$ & 10 & 8 & 18 \\
\hline No (> 500 cells/ $\mu \mathrm{L})$ & 39 & 238 & 277 \\
\hline Total & 49 & 246 & 295 \\
\hline
\end{tabular}

patients' recover and the decline of opportunistic infection. Significant HIV associated morbidity and mortality had been reported in pre-ART era. Following the introduction of HAART, however, the quality of life and disease related outcomes have been improved especialty in high HIV burden countries like Ethiopia [7].

On the other hand, we reported that the prevalence of virologic treatment failure was $16.6 \%$ (95\% CI 12.5-20.9) among participants. The result was comparable to reports of previous studies in Gondar (14.7\%) [8] and Addis Ababa (19.8\%) [9]. Likewise, our report was consistent with findings in Uganda (14.5\%) [10], India (12.7\%) [11], Shenzhen, China (13.4\%) [12], Haiti (14.2\%) [13]. On the other hand, our result was higher when compared to the WHO 2015-2020 target of 10\% virological treatment failure among HIV-1 positive patients with ART follow-ups [7]. Our finding was also higher than what were reported by other Ethiopian studies (5.3 to 11.5\%) [14-17]. The reasons for the higher failure might be poor adherence and longer duration on ART. Variations in virological failure might be related to the WHO guideline which varies over time. For instance, in our study virological failure was defined as viral load above $1000 \mathrm{copy} / \mathrm{ml}$ based on the 2016 WHO guideline [7]. However, some researches defined virological failure as a viral load $>400$ copy/ $\mathrm{ml}$ in line with previous WHO guideline [18]. If studies were done on records, the results may be over estimated because patients are tested only when they are suspected to develop treatment failure, not on routine basis.

Patients with poor adherence had above six times higher odds to develop treatment failure $(\mathrm{AOR}=6.367$, 95\% CI 2.355-17.2, $\mathrm{P}=001$ ) compared to those who adhere. Poor adherence leads to a low level of antiretroviral effect in the body, and this causes insufficient to suppress viral replication, finally resulting in treatment failure. In addition, individuals with CD $4+$ count $<500$ cells $/ \mu \mathrm{L}$ were also nearly five times more likely to develop virological treatment failure (AOR: $=4.78,95 \%$ CI 1.155-19.77, $\mathrm{P}=0.031$ ) as opposed to those who had greater CD4+counts. It is evident that a high degree of viral replication is common among patients with a decreased level of CD4 count and subsequently leads to treatment failure.

In the present study, patients with shorter (6-24 months) treatment duration were found to be $52 \%$ less likely to develop treatment failure (AOR: 0.48 , 95\% CI $0.012-0.973, \mathrm{P}=0.048$ ) in comparison to those with $>72$ months on treatment. Reasonably, if the duration of ART increases, the emergence of HIV-DR strain is expected as a result of HIV error-prone replication, mutation rate, and viral recombination [19]. Over time, acquired drug resistance (during on ART) might cause treatment failure; so patients with shorter duration 
(6-24 months) on ART have a less likely incidences of acquiring drug resistant viruses than those with longer (>73 month) among exposure to ART. Thus a high burden of a drug-resistant virus with an increased viral load is expected among patients with more months than with lesser months on ART $[19,20]$. Besides, the possible reason might be that as the duration of ART increases, the likelihood of poor adherence, drug interruption, and drug side effects also increase.

Furthermore, immunological failure was found to be 6.1\% (95\% CI 3.4-9.5). The finding was in line with those of studies conducted in Ethiopia and reported 3.8-6.8\% $[16,21,22]$. However, it was lower than the results of other studies in Ethiopia 15-21\% [9, 14, 23], Tanzania19\% [24], and Shenzhen China 18.4\% [12]. Our work showed a lower immunological failure than some studies in Ethiopia and abroad. The possible reason for the low result might be the low sensitivity of the test. Immunological failure may also be related to the WHO guideline which varies over time. For instance, in our study immunological failure was defined as a fall of $\mathrm{CD} 4+$ count below 250 cells/ $\mu \mathrm{L}$ following clinical failure or as a persistent CD 4 + count below 100 cells/ $\mu \mathrm{L}$ based on the $2016 \mathrm{WHO}$ guideline. However, a former research defined immunological failure as a fall of CD4 + count to baseline or below severe immune suppression $(\mathrm{CD} 4+$ count $<200$ cells $/ \mu \mathrm{L})$ in line with previous WHO guidelines.

In the current study, immunologic failure had low predictive values for detecting the virologic failures. The reasons might be low prevalence of immunological failure and test inaccuracy. Compared to the golden standard virologic failure immunologic failure, sensitivity, specificity, PPV and NPV were 20.4\%, 96.7\%, 55.5\%, and 86\% respectively. Several studies also pointed out the low performance of immunological criteria for prediction of HIV/AID treatment failure [25-27]. The low sensitivity of the immunological criteria for identifying virological failure could result in delayed switching to second-line treatment with the accumulation of resistance mutations; the low positive predictive value may incorrectly identify patients as needing second-line treatment, while they are virologically suppressed.

\section{Limitations}

The finding of the study is limited owing to the fact that specific drug resistance was not confirmed using genotypic method for resistance and susceptibility, for lack of resources. Being a institutional-based study, the result may not also be generalized to wider population. Despite its limitation, however, the work, we believe, provides important information which would be useful for the ART treatment programs in the country.

\section{Conclusion}

In the present study, the burden of antiretroviral treatment failure according to $\mathrm{WHO}$ virological criteria was more than the $10 \%$ WHO target failure. The Immunological test had low predictive values for detecting treatment failure compared to viral load estimation as a standard method. Poor adherence, $\mathrm{CD} 4+$ count $<500$ cells $/ \mu \mathrm{L}$ and prolonged duration on ART were significant for virological failure. Therefore, our finding indicates the need for more focus and effort from the study area hospital and concerned bodies on significant risk factors to maximize the successes of patients' health by preventing, enhance early detection and monitoring of antiretroviral treatment failure and control further complications.

\section{Acknowledgements}

We thank all the study participants, data collectors and supervisors for their participation. This manuscript was presented at the Department of Medical Microbilogy, School of Biomedical and Laboratory Sciences, University of Gondar for a partial fulfilment of the requirements for MSc degree. We also thank Mr. Demeke Desu for his language editorial services.

\section{Authors' contributions \\ JN designed and implemented the study, collected data, carried out statisti- cal analysis, interpreted data, and drafted the manuscript. ST, YM, CR and SE participated in data analysis, and interpretation and review manuscript. All authors contributed data analysis, drafting, and critically revising the paper, and approved of the final version for publication, and agreed to be account- able for all aspects of the work. All authors read and approved the final manuscript.}

\section{Funding}

No funding source.

\section{Availability of data and materials}

The datasets used and/or analyzed during the study are available from the corresponding author on reasonable request.

\section{Ethics approval and consent to participate}

Before the beginning of the study, ethical approval was obtained from the Institutional Review Committee of the School of Biomedical and Laboratory Sciences, the University of Gondar (UOG), and further the investigation was conducted in accordance with the Helsinki declaration. Permission was issued by Tefera Hailu Memorial Hospital. Each respondent was informed about the objective and the importance of the study to evaluate their treatment outcomes, and related factors. Data obtained from the participants was kept confidential by using codes instead of any personal identifiers. Before specimen collection, informed and signed consent was obtained from adult participants. Written informed consent for children (under 16 years) was obtained from their parents or guardian. The results were communicated to physicians in attendance.

\section{Consent for publication}

Each study participant was informed and signed for publication.

Competing interests

The authors declare that they have no competing interests in this work.

\section{Author details}

${ }^{1}$ Department of Medical Microbiology, School of Biomedical and Laboratory Sciences, College of Medicine and Health Sciences, University of Gondar, PO Box 196, Gondar, Ethiopia. ${ }^{2}$ Department of Pathology, Faculty of Medicine, University of New South Wales, Sydney, New South Wales, Australia. 
Received: 4 April 2020 Accepted: 2 July 2020

Published online: 10 July 2020

\section{References}

1. Global HIV \& AIDS statistics. Global HIV \& AIDS statistics_fact sheet 2018. http://www.unaids.org/en/resources/fact-sheet Accessed 5 Nov 2018.

2. World Health Organization. Global update on HIV treatment: results, impact and opportunities. WHO; 2017 Accessed 6 Dec 2018.

3. Fethia K SM, Kassu K, Shewaminale Y, Zelalem T. National guidelines for comprehensive HIV prevention, care and treatment federal minstry of health, Ethiopia 2017. 5th ed.: https://aidsfree.gov/ethiopia_art_quide lines_2017. Accessed 7 Jan 2019

4. Kassa D, Gebremichael G, Alemayehu Y, Wolday D, Messele T, van Baarle D. Virologic and immunologic outcome of HAART in Human Immunodeficiency Virus (HIV)-1 infected patients with and without tuberculosis (TB) and latent TB infection (LTBI) in Addis Ababa, Ethiopia. AIDS Res Ther. 2013;10(1):18

5. Roberts T, Cohn J, Bonner K, Hargreaves S. Scale-up of routine viral load testing in resource-poor settings: current and future implementation challenges. Clin Infect Dis. 2016;62(8):1043-8.

6. Assefa A, Gelaw B, Getnet G, Yitayew G. The effect of incident tuberculosis on immunological response of HIV patients on highly active anti-retroviral therapy at the university of Gondar hospital, northwest Ethiopia: a retrospective follow-up study. BMC Infect Dis. 2014;14(1):468.

7. World Health Organization. Consolidated guidelines on HIV prevention, diagnosis, treatment and care for key populations. Geneva: World Health Organization; 2016

8. Ayele G, Tessema B, Amsalu A, Ferede G, Yismaw G. Prevalence and associated factors of treatment failure among HIV/AIDS patients on HAART attending University of Gondar Referral Hospital Northwest Ethiopia. BMC Immunol. 2018:19(1):37.

9. Yimer YT, Yalew AW. Magnitude and predictors of anti-retroviral treatment (ART) failure in private health facilities in Addis Ababa, Ethiopia. PLoS ONE. 2015;10(5):e0126026.

10. von Braun A, Sekaggya-Wiltshire C, Scherrer AU, Magambo B, Kambugu A, Fehr J, et al. Early virological failure and HIV drug resistance in Ugandan adults co-infected with tuberculosis. AIDS Res Ther. 2017;14(1):1.

11. Karade SK, Ghate MV, Chaturbhuj DN, Kadam DB, Shankar S, Gaikwad $\mathrm{N}$, et al. Cross-sectional study of virological failure and multinucleoside reverse transcriptase inhibitor resistance at 12 months of antiretroviral therapy in Western India. Medicine. 2016;95(37).

12. Huang $P$, Tan J, Ma W, Zheng H, Lu Y, Wang N, et al. Outcomes of antiretroviral treatment in HIV-infected adults: a dynamic and observational cohort study in Shenzhen, China, 2003-2014. BMJ OPEN. 2015;5(5):e007508.

13. Jean Louis F, Buteau J, François K, Hulland E, Domerçant JW, Yang C, et al. Virologic outcome among patients receiving antiretroviral therapy at five hospitals in Haiti. PLoS ONE. 2018;13(1):e0192077.

14. Bokretsion GB, Endalkachew N, Getachew KA. HIV/AIDS treatment failure and its determinant factors among first line HAART patients at FelegeHiwot Referral Hospital, Bahir Dar, Northwest Ethiopia. J AIDS Clin Res. 2017;8(11):37
15. Abdissa A, Yilma D, Fonager J, Audelin AM, Christensen LH, Olsen MF, et al. Drug resistance in HIV patients with virological failure or slow virological response to antiretroviral therapy in Ethiopia. BMC Infect Dis. 2014;14(1):181

16. Hailu GG, Hagos DG, Hagos AK, Wasihun AG, Dejene TA. Virological and immunological failure of HAART and associated risk factors among adults and adolescents in the Tigray region of Northern Ethiopia. PLoS ONE. 2018;13(5):e0196259.

17. Mekuria LA, Nieuwkerk PT, Yalew AW, Sprangers MA, Prins JM. High level of virological suppression among HIV-infected adults receiving combination antiretroviral therapy in Addis Ababa, Antivir Ther. 2016;21 (5):385-96.

18. World Health Organization. Global update on the health sector response to HIV, 2014. 2014.

19. Chen M, Ma Y, Duan S, Xing H, Yao S, Su Y, et al. Genetic diversity and drug resistance among newly diagnosed and antiretroviral treatment-naive HIV-infected individuals in western Yunnan: a hot area of viral recombination in China. BMC Infect Dis. 2012;12(1):382

20. Liégeois F, Vella C, Eymard-Duvernay S, Sica J, Makosso L, MouingaOndémé $\mathrm{A}$, et al. Virological failure rates and HIV-1 drug resistance patterns in patients on first-line antiretroviral treatment in semirural and rural Gabon. J Int AIDS Soc. 2012;15(2):17985.

21. Biset AM, Dawit K, Assefa B, Samson G, Derso al. Ee T. First-line antiretroviral treatment failure and associated factors in HIV patients at the University of Gondar Teaching Hospital, Gondar, Northwest Ethiopia. HIV/ AIDS. 2016:8:141.

22. Bayou B, Sisay A, Kumie A. Assessment of the magnitude and associated factors of immunological failure among adult and adolescent HIV-infected patients in St. Luke and Tulubolo Hospital, Oromia Region, Ethiopia. Pan Afr Med J. 2015;21(1):291

23. Yayehirad AM, Mamo WT, Gizachew AT, Tadesse AA. Rate of immunological failure and its predictors among patients on highly active antiretroviral therapy at Debremarkos hospital, Northwest Ethiopia: a retrospective follow up study. J AIDS Clin Res. 2013:4(5):5474103.

24. Vanobberghen FM, Kilama B, Wringe A, Ramadhani A, Zaba B, Mmbando $D$, et al. Immunological failure of first-line and switch to secondline antiretroviral therapy among HIV-infected persons in T anzania: analysis of routinely collected national data. Tropical Med Int Health. 2015;20(7):880-92.

25. Reynolds SJ, Nakigozi G, Newell K, Ndyanabo A, Galiwongo R, Boaz I, et al. Failure of immunologic criteria to appropriately identify antiretroviral treatment failure in Uganda. AIDS. 2009;23(6):697.

26. Keiser O, MacPhail P, Boulle A, Wood R, Schechter M, Dabis F, et al. Accuracy of WHO CD4 cell count criteria for virological failure of antiretroviral therapy. Tropical Med Int Health. 2009;14(10):1220-5.

27. Kantor R, Diero L, DeLong A, Kamle L, Muyonga S, Mambo F, et al. Misclassification of first-line antiretroviral treatment failure based on immunological monitoring of HIV infection in resource-limited settings. Clin Infect Dis. 2009;49(3):454-62.

\section{Publisher's Note}

Springer Nature remains neutral with regard to jurisdictional claims in published maps and institutional affiliations.

Ready to submit your research? Choose BMC and benefit from

- fast, convenient online submission

- thorough peer review by experienced researchers in your field

- rapid publication on acceptance

- support for research data, including large and complex data types

- gold Open Access which fosters wider collaboration and increased citations

- maximum visibility for your research: over 100M website views per year

At BMC, research is always in progress.

Learn more biomedcentral.com/submissions 